\title{
The utility of neutrophil gelatinase- associated Lipocalin (NGAL) as a marker of acute kidney injury (AKI) in critically ill patients
}

\author{
Shabnum Khawaja ${ }^{1}$, Lena Jafri ${ }^{1}$, Imran Siddiqui ${ }^{1}$, Madiha Hashmi ${ }^{2}$ and Farooq Ghani ${ }^{1 *}$
}

\begin{abstract}
In current clinical practice, Serum Creatinine ( $\mathrm{SCr}$ ) is a commonly used marker for the diagnosis of acute kidney injury (AKI). Unfortunately, due to a delayed increase in $\mathrm{SCr}$, it is unable to accurately estimate the timing of the injury. The purpose of this study was to assess the ability of plasma neutrophil gelatinase-associated lipocalin (pNGAL) to predict AKI in critically ill adult patients. The study was conducted at the Section of Chemical Pathology, Department of Pathology\& Laboratory Medicine in collaboration with Department of Anesthesiology, at Aga Khan University Hospital in Karachi, Pakistan. Subjects in the age groups of18 to 60, that were admitted into the intensive care unit (ICU) with suspected sepsis were enrolled in this study.AKI was labeled by using Risk-Injury-Failure-loss-End Stage (RIFLE) criteria. Forty-eight patients, mean age being $46.5 \pm 16.3$, were recruited over a nine-month period. Multiple blood samples were collected from each patient at $12 \mathrm{~h}, 24 \mathrm{~h}$, and $48 \mathrm{~h}$. A total of $52.1 \%(n=24)$ of ICU patients suspected of sepsis had developed AKI. Baseline characteristics of subjects with AKI were compared to those without AKI. Statistically significant difference was noted in gender ( $p$-value $<0.05)$ and PNGAL $(p$-value $<0$. 001). However, no significant differences were seen with respect to age, in patients with and without AKI. The area under the curve (AUC) at $12 \mathrm{hr}$ was $0.82(95 \% \mathrm{Cl} 0.68-0.96)$ with a sensitivity of $70.8 \%$ and specificity of $90.9 \%$. While AUCs at $24 \mathrm{~h}$ was $0.86(95 \% \mathrm{Cl} 0.74-0.97)$ with a sensitivity of $78.5 \%$ and specificity of $88.8 \%$. Furthermore, there was a positive correlation between pNGAL and the length of ICU stay $(r=0.98)$. Non-survivors or expired patients had higher median pNGAL170 (202-117) $\mathrm{ng} / \mathrm{ml}$ as compared to survivors $123(170-91) \mathrm{ng} / \mathrm{ml}$. In conclusion, pNGAL is an early predictor of AKI in a heterogeneous adult ICU population. Plasma NGAL allows the diagnosis of AKI $48 \mathrm{~h}$ prior to a clinical diagnosis based on RIFLE criteria. Early identification of high-risk AKI in patients may allow earlier initiation of therapies and improve patient outcome.
\end{abstract}

Keywords: Acute kidney injury (AKI), Sepsis, Plasma neutrophil gelatinase associated Lipocalin (pNGAL), Intensive care unit (ICU)

\section{Introduction}

Acute kidney injury (AKI) is a rapid loss of kidney function following failure to maintain fluid, acid-balance, and electrolyte homeostasis [1]. Acute kidney injury alone complicates 7.2 to $20 \%$ of hospitalized patients and $13-$ $78 \%$ of intensive care unit (ICU) patients [2-8]. Critically ill patients with concomitant AKI have a poor

\footnotetext{
* Correspondence: farooq.ghani@aku.edu

${ }^{1}$ Department of Pathology\& Laboratory Medicine, Aga Khan University Hospital (AKUH), Stadium Road, P.O. Box 3500, Karachi 74800, Pakistan Full list of author information is available at the end of the article
}

prognosis and a high mortality rate. Sepsis is a common cause of AKI in critically ill patients and various observational studies have found that sepsis contributes 30 $50 \%$ of all AKI cases [9].

In the last few decades, serum Creatinine ( $\mathrm{SCr}$ ) is used for the diagnosis of AKI in common practice, but $\mathrm{SCr}$ is a functional marker and not an ideal biomarker to identify AKI. The values of SCr are influenced by multiple non-renal factors, like age, gender, muscle mass and metabolism, dietary habits, medications, and hydration status [9]. There is a considerable delay in increase of $\mathrm{SCr}$

(c) The Author(s). 2019 Open Access This article is distributed under the terms of the Creative Commons Attribution 4.0 International License (http://creativecommons.org/licenses/by/4.0/), which permits unrestricted use, distribution, and 
after AKI and it does not reflect the actual decrease in glomerular filtration rate (GFR). Additionally, SCr may not rise until more than half of the kidney function has been lost. Delay in prompt diagnosis and management of AKI may cause irreversible kidney damage. RIFLE criterion was proposed by Acute Dialysis Outcome Initiative(ADQI) group in order to have a uniform standard for diagnosis and classification of AKI, including Risk(R), Injury (I), Failure (F), Loss (L), and End-Stage (E) renal disease as a tool for qualifying and quantifying the severity of AKI [10]. The RIFLE based on either two-fold increase in the SCr from baseline, or GFR decrease by $50 \%$, or urine output $<0.5 \mathrm{ml} / \mathrm{kg}$ per hour for $12 \mathrm{~h}$. Many studies in the literature have applied SCr criteria (RIFLE-SCr), but there are some inherent limitations. First, it is based on relative changes in serum or plasma $\mathrm{Cr}$, due to varying extrarenal clearance; $\mathrm{Cr}$ is a late and unreliable responder to GFR alterations. Second, $\mathrm{Cr}$ is a small molecule (113 Da) and may pass through the glomerular filter freely even when glomerular pores are moderately narrowed [11]

There is a need for a reliable AKI biomarker, which should be sensitive, specific, depict early change following kidney injury, easy to measure, and does not require administration of an exogenous substance. Many new promising AKI biomarkers have been identified and one such promising biomarker is plasma Neutrophil Gelatinase-Associated Lipocalin (pNGAL) [12]. Numerous studies have been done on this biomarker, but it is still controversial to use this biomarker in the clinical setting as an AKI marker. Metanalysis done by An Zhang and his colleagues (2016) stated that" Utility of NGAL to predict the occurrence of AKI in septic patients remains controversial" [13]. Therefore, the objective of this study is to assess the ability of pNGAL to predict early AKI in critically ill adult patients presenting with sepsis.

\section{Material and methods}

\section{Patient recruitment}

A cross-sectional study was conducted at the Section of Chemical Pathology, Department of Pathology \& Laboratory Medicine in collaboration with the Department of Anesthesiology at Aga Khan University Hospital in Karachi, Pakistan during December 2014 to August 2015. Patient clinical details along with demographics and relevant biochemical data were recorded on a structured proforma within $12 \mathrm{~h}$ of admission to intensive care unit (ICU).

\section{Inclusion criterion}

All subjects that are between the ages of 18-60, admitted to the ICU at Aga Khan University Hospital with suspected sepsis were included in the study. Sepsis was defined as per systemic inflammatory response syndrome (SIRS) criterion if patients presented with: body temperature $>38^{\circ} \mathrm{C} \quad\left(100.4^{\circ} \mathrm{F}\right)$ or $<36^{\circ} \mathrm{C} \quad\left(96.8^{\circ} \mathrm{F}\right)$, heart rate $>90$ beats per minute, respiratory rate $>20$ breaths per minute or arterial carbon dioxide tension $\left(\mathrm{PaCO}_{2}\right)$ $<32 \mathrm{mmHg}$, Abnormal white blood cell count $(>12,000 /$ $\mu \mathrm{L}$ or $<4000 / \mu \mathrm{L}$ or $>10 \%$ immature and white blood cell count $>12,000 \times 10[8] / \mathrm{L}$ or $<4000 \times 10[8] / \mathrm{L}$. $[11,12]$

\section{Prediction of AKI and calculation of baseline serum creatinine}

Using Risk-Injury-Failure-Loss-End Stage (RIFLE-SCr) proposed by the Acute Dialysis Quality Initiative (ADQI) group [14]. A twofold increase in SCr from baseline value was considered as AKI [15]. Cut off $150 \mathrm{ng} / \mathrm{ml}$ of Plasma NGAL used for the Prediction of Acute kidney injury $[13,16]$.

Patient's baseline serum Creatinine (bSCr) levels were calculated by using the Modification of Diet in Renal Disease (MDRD) equation proposed by the Acute Dialysis Quality Initiative (ADQI) working group by using formula [17]:

Serum Creatinine $=\left(75 / 186 \times\left(\right.\right.$ age $\left.^{-0.203}\right) \times(0.742$ if female $) \times(1.21$ if black $)])^{-0.887}$

\section{Exclusion criterion}

Pregnant females, patients with known chronic kidney disease, patients on hemodialysis, renal transplant recipients, and those with known kidney malignancy were excluded. Death of patients or early ICU discharged patients was also excluded from this study.

\section{Blood sampling and biochemical analysis}

Serial blood sampling was done for pNGAL in the following manner: first within $12 \mathrm{~h}$ of admission to ICU, second after $24 \mathrm{~h}$, and a third sample was drawn after $48 \mathrm{~h}$ of the first sample. Three to four milliliters of blood was drawn each time in ethylenediaminetetraacetic-acid (EDTA) vacuutainer. Blood samples were centrifuged at $3000 \mathrm{rpm}$ for $15 \mathrm{~min}$, aliquoted (for what> be specific), and stored at $-80{ }^{\circ} \mathrm{C}$ until analysis. The pNGAL was analyzed by fluorescence immunoassay on Triage ${ }^{\circledR}$ Meter Proby Alere Diagnostics point of care analyzer, CA, US. Two levels of manufacturer-provided quality controls (low and high) were run with each batch of analysis.

\section{Statistical analysis}

Data was analyzed using the Statistical Package for the Social Sciences (SPSS version 19.0). Frequency and percentages were calculated for gender. Mean, standard deviation, and median with interquartile ranges was computed for a continuous variable, the age of the patients, duration of hospital stay, and pNGAL. The pNGAL levels between patients with and without AKI 


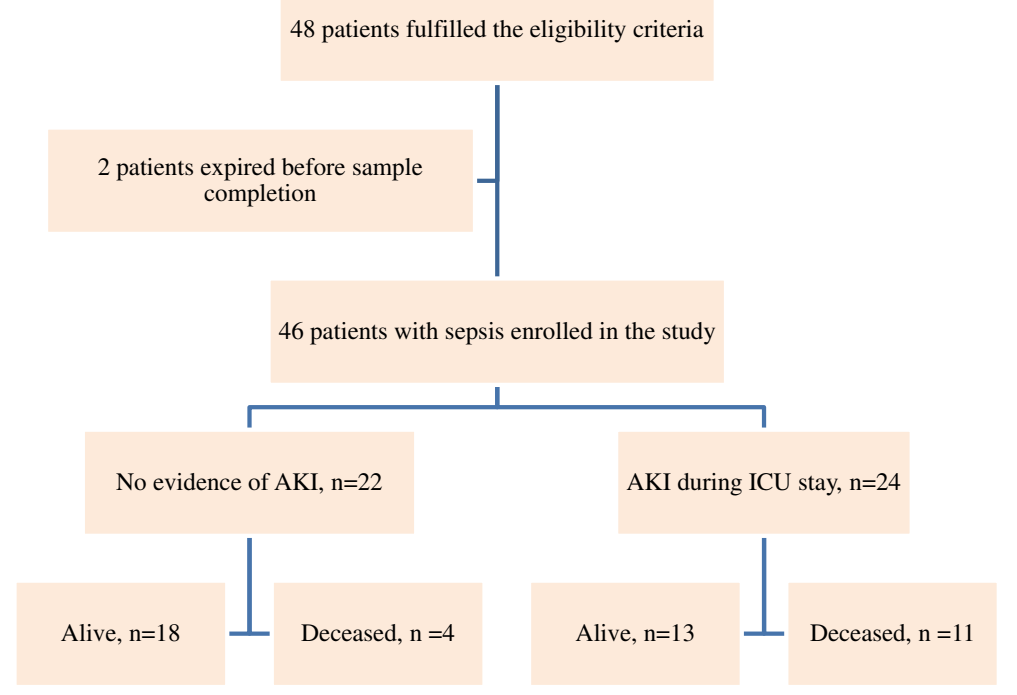

Fig. 1 Profile of recruitment and outcome of study group

were compared by independent $\mathrm{t}$-test. The diagnostic accuracy of pNGAL to predict AKI in critically ill patients of ICU was assessed by applying Receiver Operator Curve (ROC) analysis and calculating the area under the curve (AUC) at 24 and $48 \mathrm{~h}$. A $p$-value of $<0.05$ was considered as statistically significant.

\section{Results}

In this prospective study, adult patients admitted into the ICU with suspicion of sepsis were recruited over a period of nine months. However, two of the 48 patients

Table 1 Demographics and clinical details of patients $(n=46)$ admitted to ICU with sepsis

\begin{tabular}{ll}
\hline Characteristics & $\mathrm{n}(\%)$ \\
\hline Males $\mathrm{n}(\%)$ & $32(69 \%)$
\end{tabular}

\section{Stratification of subjects as per WHO classification}

Normal

$1634.8 \%)$

Overweight

$23(50 \%)$

Obese

7 (15.2\%)

\section{Comorbids}

No Comorbids

DM, HTN and Cardiovascular Disease

Cardiovascular Disease

DM

Pulmonary Disease

Liver Disease

Malignancy

1 (2.2)

Abbreviations: intensive care unit, ICU basal metabolic index, BMI diabetes mellitus, DM hypertension, HTN expired before blood sampling was completed. Forty-six patients fulfilled the criteria for sepsis and were subjected to blood sampling and biomarker analysis (Fig. 1). The mean age of patients $(n=46)$ was $46.5 \pm 16.3$ years with the majority being males. Mean BMI of the patients was $26.2 \pm 4.8 \mathrm{~kg} / \mathrm{m}$ [9]. Baseline mean SCr of males and females was $1.1 \pm 0.1 \mathrm{mg} / \mathrm{dl}$ and $0.8 \pm 0.7 \mathrm{mg} / \mathrm{dl}$ respectively. Table 1 describes the general characteristics and clinical details of the study group. Median ICU stay of the study group was 6 days (4-13 days).

Plasma NGAL levels increased by $41.3 \%(n=19)$ at 12 h, $50 \%(n=23)$ at $24 \mathrm{~h}$ and $54.3 \%(n=25)$ at $48 \mathrm{~h}$ of ICU admission. Using RIFLE criteria, a total of $52.1 \%(n=24)$ of ICU patients developed AKI during their ICU stay. Out of these pNGAL levels increased by $70.8 \%(n=17)$ at $12 \mathrm{~h}$ of ICU admission and $79 \%(\mathrm{n}=19)$ patients at $24 \mathrm{~h}$ of ICU admission. However, 5 patients were mislabeled by pNGAL as AKI. SCr reached endpoint at $48 \mathrm{~h}$ of ICU stay with median $\mathrm{SCr}$ was $2.3(3.1-2.1) \mathrm{mg} / \mathrm{dl}$ at $48 \mathrm{~h}$ of ICU admission.

Baseline characteristics of subjects with AKI were compared with those without AKI. Statistically, a significant difference was noted in gender (pvalue $<0.05$ ) and pNGAL (value< 0.001 ) between patients with (Fig. 2) and without AKI (Table 2). However, no significant differences were seen in age, between patients with and without AKI. AUCs at12 hours was 0.82 (95\%CI 0.68 0.96 ) with sensitivity of $70.8 \%$ and specificity of $90.9 \%$. AUCs at $24 \mathrm{~h}$ was $0.86(95 \% \mathrm{CI} 0.74-0.97)$ with the sensitivity of $78.5 \%$ and specificity of $88.8 \%$. There was a positive correlation between pNGAL and the duration of the ICU stay $(r=0.98)$. Mortality rate was $32.6 \%(n=15)$, while $67.3 \%(n=31)$ of patients were shifted to the wards 


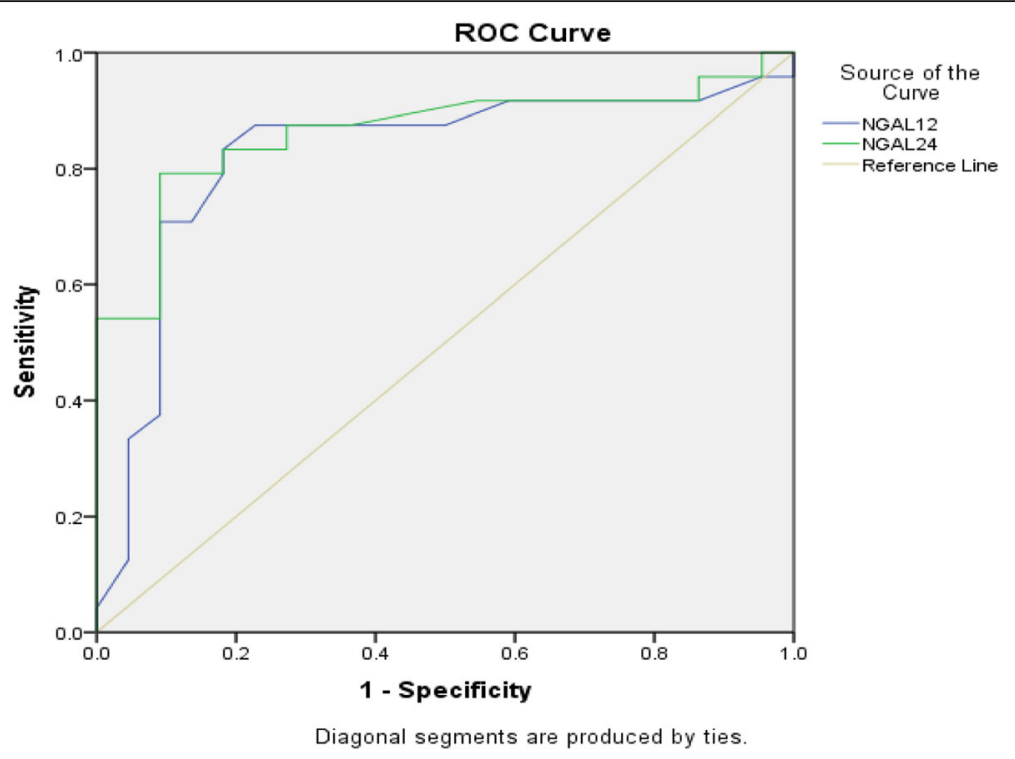

Fig. 2 ROC curve of pNGAL at the 12 and $24 \mathrm{~h}$ time points

from the ICU. Amongst expired patients12hour median pNGAL was $170(202-117) \mathrm{ng} / \mathrm{ml}$ as compared to survivors which were $123(170-91) \mathrm{ng} / \mathrm{ml}$.

\section{Discussion}

The utilization of pNGAL for the prediction of AKI was studied. All patients that were admitted with suspected sepsis not having AKI on admission were used as the study subjects to analyze p NGAL for the prediction of AKI. It was observed that pNGAL levels were significantly higher in patients who developed AKI in comparison who did not develop AKI ( $p$-value< 0.05).This allowed to distinguish AKI patients from non-AKI patients. A similar study performed by Soto and his colleagues (2013), stated that highest median levels of pNGAL seen in patients with AKI (146-174 $\mathrm{ng} / \mathrm{ml}$ at various points) increased level with AKI severity (207-244 ng/ml) [18]. Another study performed by Usman et al. in 2013 also reported nearly similar median (IQR) of pNGAL of $170 \mathrm{ng} / \mathrm{ml}(126-274$ $\mathrm{ng} / \mathrm{ml}$ ) in patients who develop AKI [19]

There is no consensus about the cutoff value of pNGAL at which AKI diagnosis can be made accurately [20].We used a cutoff of $150 \mathrm{ng} / \mathrm{ml}$ to predict AKI, which was similar cutoff used by Camou et al. in 2013 [16] and Wang et al. [21] in 2014 to predict AKI. A systematic review and meta-analysis done by Zhang et al. [13] which included the studies of Yamashita et al. [22] and Dai et al. [23] reported diagnostic ability of pNGAL with AUCs of 0.94 (95\% CI, 0.88-0.97) and 0.92 (95\% CI, 0.84-0.96) respectively for plasma NGAL to predict AKI in septic patients similar to our findings. Azrina ralib et al. reported similar AUC for pNGAL for the diagnosis of AKI, 0.81 (95\%CI 0.74 to 0.87) [24].

NGAL was originally isolated from secondary granules of human neutrophils as a $25 \mathrm{KDa}$ protein covalently linked to matrix metalloproteinase-9 (MMP-9) in human neutrophils [25]. It is highly induced proteins in the

Table 2 Biochemical characteristics of patients with and without AKI

\begin{tabular}{llll}
\hline Variables & \multicolumn{2}{l}{ Patients with suspected sepsis $(n=46)$} & $p$-value \\
\cline { 2 - 3 } & $\begin{array}{l}\text { AKl } \\
n=24\end{array}$ & $\begin{array}{l}\text { Non-AKl } \\
n=22\end{array}$ \\
\hline Male n (\%) & $18(39.1 \%)$ & $14(30 \%)$ & $<0.05$ \\
Mean WBC count $\times 10[8]$ & $16.0 \pm 7.1$ & $16.7 \pm 6.3$ & $>0.05$ \\
Median pNGAL at $12 \mathrm{~h}(\mathrm{ng} / \mathrm{ml})$ & $185(262-142)$ & $130(120-70)$ & $<0.05$ \\
Median pNGAL at $24 \mathrm{~h}(\mathrm{ng} / \mathrm{ml})$ & $400(585-185)$ & $133(140-60)$ & $<0.05$ \\
Median pNGAL at $48 \mathrm{~h}(\mathrm{ng} / \mathrm{ml})$ & $597(452-1050)$ & $4(16.6 \%)$ & $>0.05$ \\
Non-Survivors & $11(45.8 \%)$ & 0.05 \\
\hline
\end{tabular}

Quantitative variables are expressed in mean \pm SD or median (IQR) and frequencies as $\mathrm{n}(\%)$. Abbreviations: acute kidney injury, AKI Plasma neutrophil Gelatinase associated Lipocalin, pNGAL, SerumCreatinine, Scr 
kidney after ischemic or nephrotoxic AKI in animal models [26]. Its levels can be detected in the plasma of patients as early as $2 \mathrm{~h}$, peak at approximately $6 \mathrm{~h}$ after injury and its levels remain elevated for as long as five days, after which they begin to decrease [18].

The study has several limitations as it was conducted at a single center with a small sample size and a strict inclusion criterion of patients with SIRS. PNGAL was measured within $12 \mathrm{~h}$ of ICU admission; however measurement within $2-4 \mathrm{~h}$ may capture earlier changes that occur with kidney injury. However, it has been observed that there were no differences in NGAL performance when measured earlier within the ED or later in the ICU. A previous study, show plasma NGAL level, especially within $12 \mathrm{~h}$ of ICU admission, is an early and accurate predictor of AKI.

\section{Conclusion}

High plasma NGAL levels noted within $12 \mathrm{~h}$ of ICU admission allows AKI diagnosis $48 \mathrm{~h}$ prior to the diagnosis based on RIFLE criteria and proves to be an early and accurate predictor of AKI. It can be utilized as an early biomarker for the detection of AKI in critically ill patients with sepsis in ICU so that potentially beneficial therapies can be initiated before irreversible kidney injury occurs.

\section{Abbreviations \\ AKI: Acute Kidney Injury; ARF: Acute Renal Failure; ATN: Acute tubular necrosis; AUC: Area under Curve; BMI: Body mass index; EDTA: Ethylene diamine-tetra-acetic-acid; GFR: Glomerular Filtrate rate; ICU: Intensive Care Unit; PNGAL: Plasma Neutrophil Gelatinase associated Lipocalin; RIFLE: Risk.Injury.Failure. End. Stage; SCr: Serum Creatinine; SPSS: Statistical package for social sciences}

\section{Acknowledgements}

This research would not have been possible without the blessings of 'Al-mighty $A L L A H^{\prime}$, for which I shall remain thankful for all my life. During the period of my study, I have associated with many people whose contribution in assorted ways in completing the research and making this presentable. It is my utmost duty and pleasure to thank all those who made this study possible. I am extremely thankful to the Section Head of Chemical Pathology Dept. (AKUH)Dr. Ayesha Habib Khan, whose encouragement, guidance, and her support from the initial to the final stage, facilitated me to develop an understanding of the subject and completing my dissertation. In addition to my Section Head, I am also thankful to my statistian ,HafsaBaloch, in her assistance and willingness to discuss ideas at all stages of the project. Collective and individual acknowledgements are also owed to my colleagues at AKU whose presence somehow everlastingly refreshed, helpful, and memorable. Lastly I offer my regards and blessings to all those who have supported me in any respect during the completion of the project.

\section{Funding}

No

\section{Dedication}

To my Mother (Late ZarinaRamzan Ali), Father (Late Ramzan Ali) and Husband (Dildar Ali).

\section{Authors' contributions}

1. SK designed the study, analyzed the data, and wrote the manuscript. 2. LJ acquired and analyzed the data, and wrote the manuscript. 3. IS critically reviewed the manuscript for intellectual content. 4. MH critically reviewed the manuscript for intellectual content. 5. FG designed the study, participated in data analysis and critically reviewed the manuscript for intellectual content. All authors read and approved the final manuscript.

Ethics approval and consent to participate

Study was conducted after seeking approval from institution's Ethical Review Committee (ERC).This study was approved by ERC of Aga Khan University (2456-Pat-ERC-13)

\section{Consent for publication}

Written informed consent was taken from all patients or their guardians if unconscious before inclusion in the study.

\section{Competing interests}

The authors declare that they have no competing interests.

\section{Publisher's Note}

Springer Nature remains neutral with regard to jurisdictional claims in published maps and institutional affiliations.

\section{Author details}

${ }^{1}$ Department of Pathology\& Laboratory Medicine, Aga Khan University Hospital (AKUH), Stadium Road, P.O. Box 3500, Karachi 74800, Pakistan.

${ }^{2}$ Department of Anesthesiology, Aga Khan University Hospital(AKUH)Stadium Road, P.O. Box 3500, Karachi 74800, Pakistan.

Received: 7 September 2018 Accepted: 31 January 2019

Published online: 22 February 2019

\section{References}

1. Dr Andrew Lewington \& Dr Suren Kanagasundaram Acute Kidney Injury Clinical Practice Guidelines UK Renal Association 5th Edn, 2011.

2. Case J, Khan S, Khalid R, Khan A. Epidemiology of acute kidney injury in the intensive care unit. Critical care research and practice. 2013.

3. Carbonell N, Blasco M, Sanjuán R, García-Ramón R, Blanquer J, Carrasco AM. Acute renal failure in critically ill patients. A prospective epidemiological study. Nefrologia. 2004;24(1):47-53.

4. Bahloul M, Ben Hamida C, Damak H, et al. Incidence and prognosis of acute renal failure in the intensive care unit. Retrospective study of 216 cases. TunisieMedicale. 2003;81(4):250-7.

5. Metnitz PGH, Krenn CG, Steltzer $\mathrm{H}$, et al. Effect of acute renal failure requiring renal replacement therapy on outcome in critically ill patients. Crit Care Med. 2002;30(9):2051-8.

6. Paudel MS, Wig N, Mahajan S, et al. A study of incidence of AKI in critically ill patients. Ren Fail. 2012:34:1217-22.

7. Katayama S, Nunomiya S, Koyama K, Wada M, Koinuma T, Goto Y, et al. Markers of acute kidney injury in patients with sepsis: the role of soluble thrombomodulin. Critical Care. 2017;21:229.

8. CalábriaBaxmann A, Ahmed MS, Marques NC, Menon VB, Pereira AB, Kirsztajn GM, et al. Influence of Muscle Mass and Physical Activity on Serum and Urinary Creatinine and Serum CystatinC. Clin J Am Soc Nephrol. 2008 Mar;3(2):348-54

9. Anto'nio Lopes J', Jorge S, Resina C, Santos C, Pereira A'I, Neves J, et al. Acute kidney injury in patients with sepsis: a contemporary analysis. International Journal of Infectious Diseases. 2009;13:176-81.

10. Thongprayoon C, Cheungpasitporn W, Kashani K. Serum creatinine level, a surrogate of muscle mass, predicts mortality in critically ill patients. J Thorac Dis. 2016;8(5):E305-11.

11. Sanjeevani S, Pruthi S, Kalra, Goel A, KalraOPRole of neutrophil gelatinaseassociated lipocalin for early detection of acute kidney injury, Int J Crit|llnInj Sci 2014; 4(3): 223-228.

12. Mårtensson J, Bell M. Oldner. A et al Neutrophil gelatinase-associated lipocalin in adult septic patients with and without acute kidney injury Intensive Care Med. 2010;36:1333.

13. Zhang A, Cai Y, Wang P-F, Qu J-N, Luo Z-C, Chen X-D, et al. Diagnosis and prognosis of neutrophil gelatinase-associated lipocalin for acute kidney injury with sepsis: a systematic review and meta-analysis. Critical Care. 2016;20:41.

14. Bellomo R, Ronco C, Kellum JA, Mehta RL, Palevsky P, the ADQI workgroup, et al. Acute renal failure - definition, outcome measures, animal models, fluid therapy and information technology needs: the Second International Consensus Conference of the Acute Dialysis Quality Initiative (ADQI) Group. Critical Care. 2004;8:R204-12. 
15. Biomarkers of AKI: A Review of Mechanistic Relevance and Potential Therapeutic Implications Joseph L. Alge and John M. ArthurCJASN January 2015, 10 (1) 147-155;

16. Camou F, Oger S, Paroissin C, Guilhon E, Guisset O, Mourissoux G, et al. Plasma neutrophil gelatinase-associated lipocalin (NGAL) predicts acute kidney injury in septic shock at ICU admission. Ann FrAnesthReanim. 2013; 32(3):157-64.

17. De Rosa S, Samoni S, Ronco C, et al. Creatinine-based definitions: from baseline creatinine to serum creatinine adjustment in intensive care. Critical Care. 2016;20:69.

18. Soto K, Papoila AL, Coelho S, Bennett M, Ma Q, Rodrigues B, Fidalgo P, Frade F. Devarajan P Plasma NGAL for the diagnosis of AKI in patients admitted from the emergency department setting. Clin J Am SocNephrol. 2013;8(12):2053-63.

19. Muhammad Usman Munir, Dilshad Ahmed Khan, Farooq Ahmad Khan, Syed Muhammad Shahab Naqvi.Comparison of urine with plasma neutrophil gelatinase associated lipocalin in detecting acute kidney injury after cardiopulmonary bypass surgery.

20. Papoila AL, Coelho S, Bennett M, Ma Q, Rodrigues B, Fidalgo P, et al. Plasma NGAL for the Diagnosis of AKI in Patients Admitted from the Emergency Department Setting Karina. Clin J Am Soc Nephrol. 2013;8:2053-63.

21. Wang $H X, M u H B$, Zheng RQ, Lin $H, Y u J Q$, Wu XY. Neutrophilgelatinaseassociatedlipocalin for the early diagnosis of sepsis in patients with acute kidney injury. J Clin Med Pract. 2014;18(21):183-4.

22. Yamashita T, Doi K, Hamasaki Y, Matsubara T, Ishii T, Yahagi N, et al. Evaluation of urinary tissue inhibitor of metalloproteinase-2 in acute kidney injury: a prospective observational study. Crit Care. 2014;18(6):716.

23. Dai X, Zeng Z, Fu C, Zhang S, Cai Y, Chen Z. Diagnostic value of neutrophi gelatinase-associated lipocalin, cystatin C, and soluble triggering receptor expressed on myeloid cells-1 in critically ill patients with sepsis-associated acute kidney injury. Crit Care. 2015;19:223.

24. Ralib A m, mat M, john W. Pickering plasma neutrophil gelatinaseassociated Lipocalin diagnosed acute kidney injury in patients with systemic inflammatory disease and sepsis. Nephrology (Carlton). 2017;22(5):412-9.

25. Corbacıoglu SK, Cevik Y, Akinci E, Uzunosmanoglu H, Dagar S, Safak T, et al. Value of plasma neutrophil gelatinase-associated lipocalin (NGAL) in distinguishing between acute kidney injury (AKI) and chronic kidney disease (CKD). Turk J Emerg Med. 2017;2017(3):85-8.

26. Devarajan P. Neutrophilgelatinase-associated lipocalin: a promising biomarker for human acute kidney injury. Biomark Med. 2010;4(2):265-80.

Ready to submit your research? Choose BMC and benefit from:

- fast, convenient online submission

- thorough peer review by experienced researchers in your field

- rapid publication on acceptance

- support for research data, including large and complex data types

- gold Open Access which fosters wider collaboration and increased citations

- maximum visibility for your research: over $100 \mathrm{M}$ website views per year

At $\mathrm{BMC}$, research is always in progress.

Learn more biomedcentral.com/submissions 